\title{
Context-dependent aggression toward non-nestmates in the ant Diacamma sp. from Japan
}

\author{
Jumpei Uematsu ${ }^{1} \cdot$ Masayuki Hayashi $^{1,2} \cdot$ Hiroyuki Shimoji $^{3} \cdot$ Michel-Olivier Laurent Salazar $^{1} \cdot$ Kazuki Tsuji $^{1}$
}

Received: 28 February 2019 / Accepted: 23 June 2019 / Published online: 10 July 2019

(c) The Author(s) 2019, corrected publication 2019

\begin{abstract}
Aggression toward competitors is a useful measure of resource ownership and defense in animals, but aggressive behavior is costly. Therefore, it is predicted that animals will display aggression only when the expected benefit to individual fitness exceeds the expected cost. In ants, when conspecific individuals belonging to different colonies encounter each other, fighting occurs, seemingly facultatively. However, the context that influences the expression of ants' aggressive behavior, especially in the field, is still largely unknown. We investigated the plasticity of aggressiveness toward non-nestmates in Diacamma sp. from Japan. Our field experiment clearly showed that the same foragers that were aggressive toward non-nestmates in the vicinity of their nest changed to be non-aggressive at greater distances from the nest. Furthermore, the size of the colony to which the foragers belonged weakly but significantly affected their aggressiveness: foragers belonging to larger colonies behaved more aggressively toward non-nestmates. We discuss the possible adaptive significance of the observed facultative aggression between conspecific non-nestmates. Digital video images related to the article are available at http:// www.momo-p.com/showdetail-e.php?movieid=momo190618ds01a and http://www.momo-p.com/showdetail-e.php?movie id $=$ momo190618ds02a.
\end{abstract}

Keywords Social insect $\cdot$ Nestmate discrimination $\cdot$ Intraspecific competition $\cdot$ Social parasitism $\cdot$ Cost and benefit

\section{Introduction}

When individuals competing for scarce resources encounter each other, they may fight. However, the expression of aggression is usually facultative (Smith and Price 1973; Axelrod and Hamilton 1981). That is, the animals display their aggression only when the expected benefit in individual

Electronic supplementary material The online version of this article (https://doi.org/10.1007/s10164-019-00611-8) contains supplementary material, which is available to authorized users.

Kazuki Tsuji

tsujik@agr.u-ryukyu.ac.jp

Jumpei Uematsu

hamachijuntaro@gmail.com

1 Faculty of Agriculture, University of the Ryukyus, Nishihara, Okinawa 903-0213, Japan

2 Western Region Agricultural Research Center, National Agriculture and Food Research Organization, Fukuyama, Hiroshima 721-8514, Japan

3 Department of Bioscience, Kwansei Gakuin University, Sanda, Hyogo 669-1337, Japan fitness exceeds the putative attack costs such as energy consumption, injury, and death (Dugatkin and Reeve 2000).

Social insects such as ants are also facultatively hostile toward non-nestmates, which are usually unrelated individuals (Hölldobler and Wilson 1990). In ants, the adaptive significance of an individual worker's behavior is mostly evaluated in terms of inclusive fitness mainly through the reproductive success of the colony (Fletcher and Ross 1985). Inclusive fitness costs of such fighting with alien ants would come from the loss of work force through mortality and energy expenses (Jaeger 1981; Cole 1986). On the other hand, the inclusive fitness benefit can be divided into two categories (Tsuji 2010, 2013): (1) the ecological benefit that contributes to obtaining and defending resources such as foods and territories that exist outside the nest, and (2) the social and genetic benefit that prevents unrelated individuals from exploiting the colony properties stored in the nest, such as work force, nutrition (foods and broods) and/or the nest itself as a refuge. Because the balance of those colony-level costs and benefits can change depending on various contexts (Amsalem and Hefetz 2011; Barbieri et al. 2015), aggressive behavior of ant workers may also be facultative. 
There are several possible scenarios for this facultative aggression. For instance, if the ecological benefits of food acquisition are the most important, ants will be most aggressive at the feeding sites. Alternatively, if the social and genetic benefits are the most important, ants might become most aggressive in the vicinity of their nest (Tsuji 2010, 2013). In some ants, for example Pristomyrmex punctatus, workers behave more aggressively toward non-nestmates in their foraging sites than at a place near the nest but outside the foraging trails (Tsuji and Ito 1986). In another example, in the facultatively social-parasitic ant, Temnothorax longispinosus, aggression by workers is more prominent in the vicinity of their nest than at a distance from it (Alloway 1980; Stuart and Herbers 2000). As other examples of plastic aggressiveness, some ants show different levels of aggressiveness toward conspecific aliens depending on whether the alien is from a neighboring colony or from a distant colony, (i.e., the "dear enemy effect" and "nasty neighbor effect"; Heinze et al. 1996; Langen et al. 2000; Newey et al. 2010). This can also be explained by the context dependence of the balance of costs and benefits (Christensen and Radford 2018).

Diacamma sp. is the only species of the genus Diacamma distributed in Japan (Morisita et al. 1989). Colonies are monodomous and monogynous, that is, with a single nest and at most a single functional queen called the gamergate in each colony (Billen and Peeters 1991), which contains 30-300 workers (Fukumoto et al. 1989; Kikuchi et al. 2008). Workers are monomorphic and forage alone (Uezu 1977). Their main habitats are open lands, such as grasslands at a forest edge (Fukumoto 1983). In a field experiment, Suwabe et al. (2007) found that Diacamma sp. did not exhibit the "dear enemy effect"; rather, workers behaved more aggressively toward non-nestmates than toward nestmates during their artificially induced encounters. However, in our field observations of natural encounters, we often observed cases where a worker timidly ran away without attacking the encountered conspecific individual - most likely to be a non-nestmate (Jumpei Uematsu, unpublished data). We therefore thought that Diacamma sp. might show context-dependent aggression.

In this study, we addressed the question of what conditions influence aggressiveness toward non-nestmates of this ant in the field. One factor that can change aggressiveness is the distance from the nest. We hypothesized that Diacamma sp. workers primarily defend social and genetic resources, because intraspecific brood stealing between neighboring colonies has been reported in Diacamma indicum in India (Paul et al. 2016), a closely related taxon to Diacamma. sp. from Japan. Another factor that can influence aggressiveness is the colony size. Theoretically, the fighting and/or defense ability of colonies and individual aggressiveness would be enhanced as colony size increases (Franks and Partridge 1993; Monnin et al. 2003; Molet et al. 2005; Plowes and Adams 2005; Cant et al. 2006; Amsalem and Hefetz 2011). The relative per capita value of an individual worker should change depending on the colony size. For example, a worker's death would be more crucial for colony survival in incipient colonies than in mature colonies. However, with a few exceptions such as those of Crosland (1990) and Stuart (1991), no study has quantitatively analyzed the influence of colony size on worker aggressiveness in the field. This is partially due to the difficulty of non-invasive estimation of ant colony size in the field. In Diacamma sp., the colony size can be accurately measured in a non-invasive way by a special trapping method in the field (as explained in the Material and methods).

In this study, we conducted field observations and experiments using Diacamma sp. to investigate how distance from the nest and colony size affects the aggressiveness of workers toward non-nestmates.

\section{Material and methods}

\section{Preparation of ant colonies}

We collected seven colonies of Diacamma sp. by using bamboo traps (a piece of shoot about $30 \mathrm{~cm}$ in length and $5 \mathrm{~cm}$ in diameter) in Sueyoshi Park, Okinawa Island, Japan $\left(26^{\circ} 23^{\prime} \mathrm{N}, 127^{\circ} 72^{\prime} \mathrm{E}\right)$, from September to early December 2017. These bamboo tubes make good nests and are regularly chosen by Diacamma sp. colonies (Fukumoto 1983). After rain, Diacamma sp. colonies often relocate to another suitable nest. So, by placing bamboo traps on the ground, colonies would relocate into them after each rain, which allowed us to collect whole colonies. We brought the colonies into the laboratory and marked all workers and gamergates (functional queens) individually with a combination of three dots from an oil paint marker (Mitsubishi Pencil Co., Ltd., Tokyo, Japan), one dot each on the dorsal regions of the anterior thorax, metathorax, and petiole (six different colors used in total). After marking, each colony was transferred to a plastic container $(44 \mathrm{~cm} \times 30 \mathrm{~cm} \times 7.5 \mathrm{~cm}$ high $)$ with a bamboo tube as a nest. They were left for $2-3$ days in a climate-controlled room $\left(25 \pm 2{ }^{\circ} \mathrm{C} ; 14 \mathrm{~L}: 10 \mathrm{D}\right)$ to acclimate to the bamboo nest. After we measured the size of each ant colony, it was transported back to Sueyoshi Park. Each bamboo nest with an ant colony was buried in the ground in an area of the park where other Diacamma sp. colonies were present. The bamboo tubes were covered completely with soil except for the entrance of the tube.

\section{Behavioral observations}

Two to three days after the bamboo nests were placed in the field, we observed the behavior of the marked workers 
outside of the nests during the daytime. We tracked individual marked workers that came out from the nest entrance. We recorded their behavioral responses when encountering non-nestmates, and the distance from the nest where the encounter occurred. An encounter was defined as a marked worker touching a non-nestmate with its antennae. The behavioral responses were designated as attacks or nonattacks to evaluate the aggressiveness of marked workers. We recorded a behavioral response as an attack when a marked worker bit or chased a non-nestmate and as a nonattack when a marked worker just touched or escaped the non-nestmate. We observed encounter events for more than 10 marked workers per colony, and 1 to 5 times per marked worker. In total, we recorded 220 behavioral responses of 101 workers from seven colonies.

During these observations, to investigate the foraging ranges of ant workers, we placed pegs $(\sim 10 \mathrm{~cm}$ in length, $0.5 \mathrm{~cm}$ in diameter) into the tracks of each marked worker on the ground until the ant went back to the nest. We then recorded the linear distance from the nest opening to the farthest peg. We tracked over 10 marked workers per colony, and 111 individuals of the seven colonies in total.

\section{Behavioral response toward presented non-nestmates}

To complement these observations, we experimentally forced encounter events in the field. We collected Diacamma sp. workers from the other colonies nesting within a 3-m radius from the marked colony by using tweezers that had been washed with acetone. The collected workers were tied with a polyester thread $(\sim 30 \mathrm{~cm}$ in length, $0.12 \mathrm{~mm}$ in diameter) around their petioles under hypothermic anesthesia (hereafter an "attached worker"). After recovering from the anesthesia, the attached workers were then used for the experiment.

We presented attached workers to marked workers outside of the marked worker's nest every 2-10 min; we brought down an attached worker softly ahead of a walking marked worker. We then recorded behavioral responses of marked workers when touching the attached workers and distance from the nest, as described above. Although attached workers were used for the test repeatedly, if an attached worker was attacked by a marked worker during an encounter, it was replaced with another individual from the same alien colony for the following tests. Ten marked workers were haphazardly selected per colony and were presented with attached workers 10 times per individual. This test was conducted for six marked colonies. A colony that had 70 workers was not used (see Results), because it moved out of our study site. In total, we recorded 600 behavioral responses from 60 individuals.

\section{Statistical analyses}

To test whether ant aggressiveness was affected by distance from the nest and colony size, behavioral response data were analyzed by a generalized linear mixed model (GLMM) with a binomial distribution and logit link function, using behavioral responses (i.e., attack or non-attack) as the response variable, distance from the nest, colony size, and the distance $\times$ colony size interaction as the fixed effects, and individual as the random effect. The significance of the effects of distance from the nest and colony size was tested using a chisquare likelihood ratio test. Likewise, in the forced encounters, the influence of distance from the nest and colony size on behavioral responses were analyzed by using a GLMM and chi-square likelihood ratio test. The statistical analyses were performed using R ver. 3.4.2 (R Developmental Core Team 2017).

\section{Results}

\section{Behavioral observation}

The numbers of workers contained in the seven marked colonies were $70,90,108,154,159,248$, and 287 . When marked workers encountered non-nestmates within a 1-m radius from the nest, they almost always attacked the nonnestmates (71 attacks/79 encounters; Fig. 1). In contrast, ants rarely attacked non-nestmates when the encounter occurred more than $2 \mathrm{~m}$ from the nest (4 attacks/81 encounters). Distance from the nest had a significant negative correlation with the aggressive behavioral responses of marked workers toward non-nestmates (regression coefficient $=-3.186$,

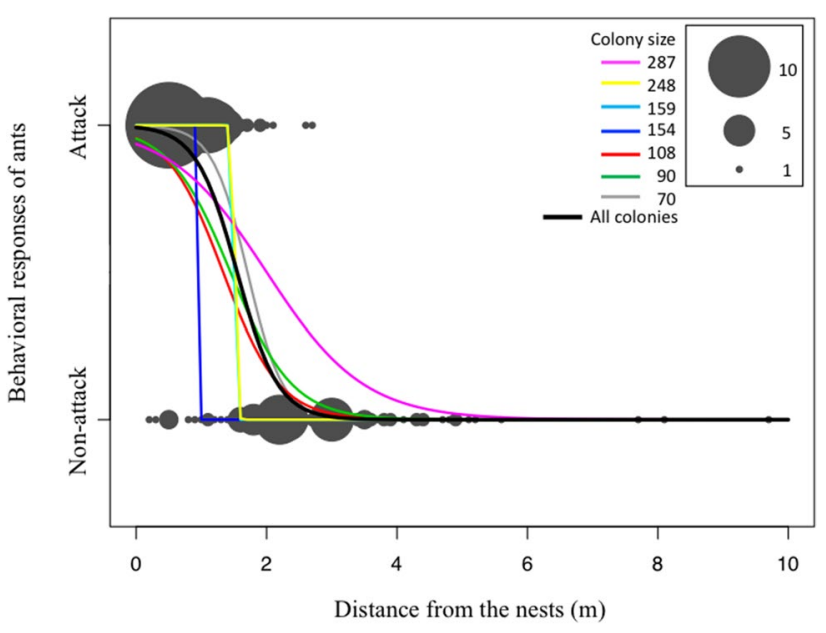

Fig. 1 The relationship between distance from the nest and aggressiveness of Diacamma sp. workers toward non-nestmates. The dot size shows the number of observations of behavioral responses $(n=220)$. Each line shows the regression curve for each colony 


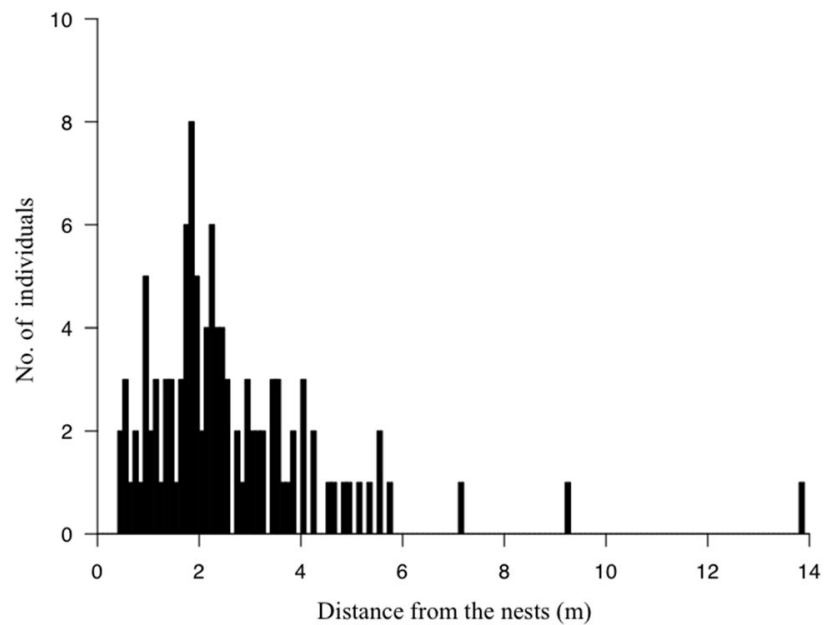

Fig. 2 The frequency distribution of the farthest distance from the nest reached in each trip of foragers. Each bar represents the number of individuals which traveled to the same maximum distance in meters $(n=111)$

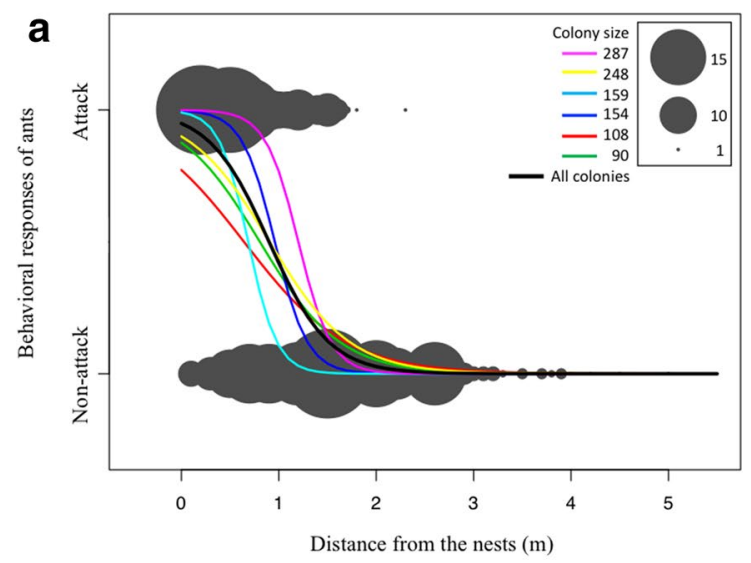

$\left.\chi^{2}=19.548, d f=1, p<0.001\right)$. This means that ants attacked non-nestmates near the attackers' own nests more frequently than when far from them. Colony size did not significantly affect the behavioral responses of ants toward non-nestmates (regression coefficient $=-0.00560, \chi^{2}=0.518, d f=1$, $p=0.471)$. The interaction between distance from the nest and colony size did not influence the behavioral responses of ants toward non-nestmates (regression coefficient $=0.00375$, $\left.\chi^{2}=0.588, d f=1, p=0.443\right)$.

Most workers walked within a 5-m radius of their nests (102/109 individuals; Fig. 2), with a few workers moving beyond this range.

\section{Behavioral response toward attached workers}

In the forced encounters, distance from the nest had a significant negative correlation with aggressive responses of marked workers toward attached workers (regression coefficient $=-2.488, \chi^{2}=13.329, d f=1, p<0.001$; Fig. 3a). When marked workers encountered attached workers near

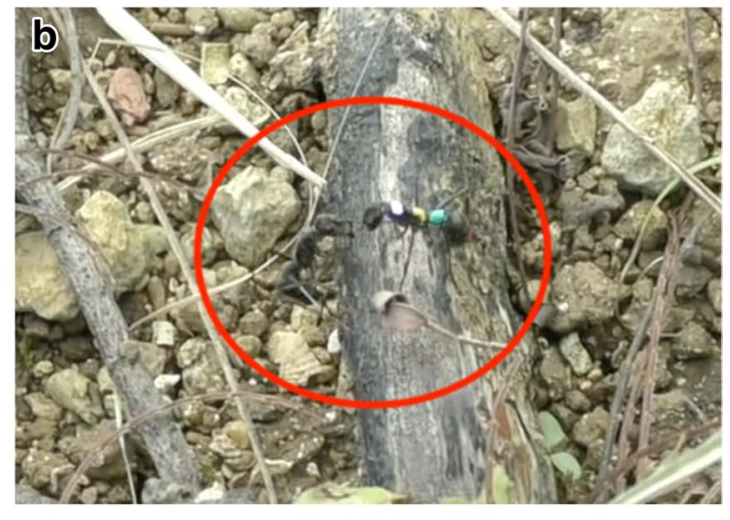

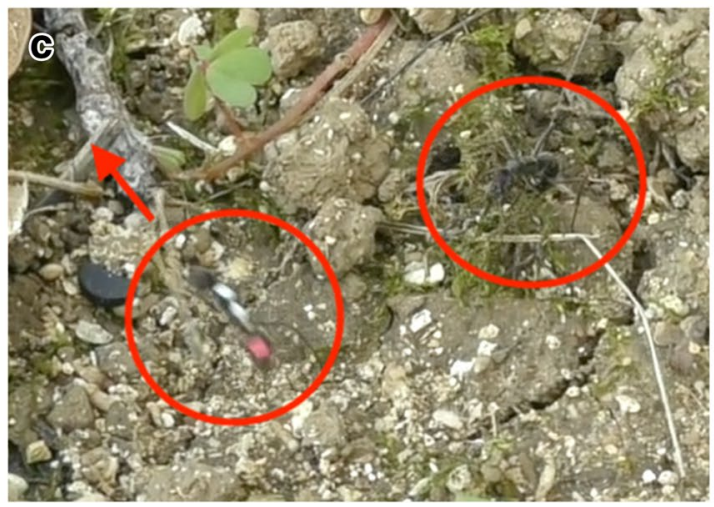

Fig. 3 Relationship between distance from the nest and aggressiveness of Diacamma sp. workers toward presented non-nestmates $(n=600)$. a The dot size shows the number of observations of behavioral responses. Each line shows the regression curve for each colony. b The aggressive behavior of a marked worker toward an attached worker (http://www.momo-p.com/showdetail-e.php?movie id=momo190618ds01a). $\mathbf{c}$ The escape behavior of a marked worker from an attached worker (http://www.momo-p.com/showdetail -e.php?movieid=momo190618ds02a). We recorded the aggressive and escape behavior of Diacamma sp. workers using a video camera (HC-WX970 M; Panasonic) 
the nest, they very often attacked (Fig. $3 b$ and S1 Electronic supplementary material: http://www.momo-p.com/ showdetail-e.php?movieid=momo190618ds01a). Colony size had a significant positive correlation with aggressive responses of ants toward non-nestmates (regression coefficient $=0.0115, \chi^{2}=4.994, d f=1, p=0.0254$ ). Thus, the aggressiveness of ants toward non-nestmates increases as colony size increases. The interaction between distance from the nest and colony size did not influence the behavioral responses of ants toward non-nestmates (regression coefficient $=-0.00480, \chi^{2}=1.517, d f=1, p=0.218$ ).

\section{Discussion}

Our results showed that workers of Diacamma sp. behaved aggressively toward non-nestmates when they encountered them near their own nest and were less aggressive far from their nest. They often escaped from non-nestmates when the encounter occurred far ( $>2 \mathrm{~m}$ ) from their nest (Fig. $3 \mathrm{c}$ and S2 Electronic supplementary material: http://www.momo-p. com/showdetail-e.php?movieid=momo190618ds02a). The fact that hostility was exerted only near the nest suggests that the adaptive significance of aggression is the protection of social and genetic resources (Tsuji 2010, 2013) as discussed in the Introduction. Aliens wandering near the nest can pose a higher threat to the colony, as they can more easily access the nest and parasitize it than alien workers walking at a distance from the nest (Hölldobler and Wilson 1990). Alternatively, if food and territorial defense were more important, ants would behave aggressively throughout their foraging area. The foraging range was within an approximate 5-m radius from the nest (Fig. 2), whereas the range within which the ants behaved aggressively was $2 \mathrm{~m}$ from the nest (Figs. 1, 3a). This suggests that food or food-based territorial defense is not the major cause of the aggression towards alien workers. Note that Diacamma sp. is an individual forager, i.e., workers seek for sparsely distributed small preys that can be hunted and brought into the nest alone (Uezu 1977). Furthermore, Diacamma. sp. workers never tend hemipteran colonies (Jumpei Uematsu, personal observation) that are usually patchily distributed and long lasting, and are thus valuable food resources for many other ants. The small benefit of defending foraging areas in comparison to that of defending their nest which has a large social and genetic resource value may mostly explain the observed facultative aggression of workers.

Our experimental data show that Diacamma sp. workers can evaluate their distance from the nest, because individuals changed behavioral response depending on the distance (see S3 Supplementary material). How do workers evaluate this? In Cataglyphis bicolor, workers use the celestial compass and stride integration to evaluate their position relative to the nest (Wittlinger et al. 2006), and Oecophylla longinoda and Cataglyphis cursor discriminate between the vicinity of the nest and other areas by using territory pheromones (Mayade et al. 1993; Hölldobler and Wilson 1978). The navigation system of Diacamma sp. workers has not yet been studied, and further work is needed to identify which cues workers use for evaluating the distance from their nest.

In the literature, there is debate about the relationship between ant aggressiveness and colony size. For instance, Crosland (1990) did not find an effect of colony size in Rhytidoponera confusa, whereas Stuart (1991) found a significant positive correlation between colony size and aggressiveness in Leptothorax ambiguus. These data were collected under laboratory conditions. Our current field study showed that colony size weakly but significantly affected ant aggressiveness, providing information supporting the latter view. We consider that the positive correlation between aggressiveness and colony size might reflect an adaptive strategy, because the marginal cost of fighting should decrease as the colony grows. When colonies are immature, a single worker's death due to fighting can cause significant damage to the colony's work force. In contrast, a large mature colony suffers less damage by the loss of a worker. Therefore, mature colonies can invest more resources to defend against social parasitism, such that workers may behave more aggressively toward non-nestmates (Alloway 1979, 1980; Stuart and Alloway 1983; Stuart 1984).

Our results suggest that Diacamma sp. workers flexibly change their aggressiveness toward conspecific aliens depending on the context, including distance from the nest and colony size. The observed spatially limited expression of aggression toward conspecific aliens might facilitate many colonies to coexist despite the hostile relationships among colonies, if an appropriate spacing between nests is achieved. In fact, nests of this species seem to be evenly distributed in the field (K. Tsuji, unpublished data). An open question is whether such flexible aggressive behavior in Diacamma sp. is also observed when they encounter heterospecific ants. Future studies should focus on this issue to understand both the adaptive significance of nestmate and species discrimination behavior and its relationship to ant community structure.

Acknowledgements We thank H. Tatsuta, K. Tsurui, Aey T. Win, Y. Okada, and H. Fujioka for their help and advice with the field experiments and analysis. Kazuki Tsuji is received the fund from the Japan Society for the Promotion of Science (JP) with the Grants numbers KAKENHI 16F16794, KAKANHI 17H01249, KAKANHI 16H04846, KAKANHI 16K14865, KAKANHI 15H02652.

\section{Compliance with ethical standards}

Conflict of interest The authors declare that they have no conflict of interest. 
Ethical approval This article does not contain any studies with human participants performed by any of the authors. All applicable international, national, and/or institutional guidelines for the care and use of animals were followed. All procedures performed in studies involving animals were in accordance with the ethical standards of the institution or practice at which the studies were conducted.

Informed consent Irrelevant.

Open Access This article is licensed under a Creative Commons Attribution 4.0 International License, which permits use, sharing, adaptation, distribution and reproduction in any medium or format, as long as you give appropriate credit to the original author(s) and the source, provide a link to the Creative Commons licence, and indicate if changes were made.

The images or other third party material in this article are included in the article's Creative Commons licence, unless indicated otherwise in a credit line to the material. If material is not included in the article's Creative Commons licence and your intended use is not permitted by statutory regulation or exceeds the permitted use, you will need to obtain permission directly from the copyright holder.

To view a copy of this licence, visit http://creativecommons.org/ licenses/by/4.0/.

\section{References}

Alloway TM (1979) Raiding behaviour of two species of slave-making ants, Harpagoxenus americanus (Emery) and Leptothorax dulotieus Wesson (Hymenoptera: Formicidae). Anim Behav 27:202-210

Alloway TM (1980) The origins of slavery in leptothoracine ants (Hymenoptera: Formicidae). Am Nat 115:247-261

Amsalem E, Hefetz A (2011) The effect of group size on the interplay between dominance and reproduction in Bombus terrestris. PLoS One 6:e18238

Axelrod R, Hamilton WD (1981) The evolution of cooperation. Science 211:1390-1396

Barbieri RF, Grangier J, Lester PJ (2015) Synergistic effects of temperature, diet and colony size on the competitive ability of two ant species. Aust Ecol 40:90-99

Billen J, Peeters C (1991) Fine structure of the gemma gland in the ant Diacamma australe (Hymenoptera, Formicidae). Belg J Zool 121:203-210

Cant MA, Llop JB, Field J (2006) Individual variation in social aggression and the probability of inheritance: theory and a field test. Am Nat 167:837-852

Christensen C, Radford AN (2018) Dear enemies or nasty neighbors? Causes and consequences of variation in the responses of groupliving species to territorial intrusions. Behav Ecol 29:1004-1013

Cole BJ (1986) The social behavior of Leptothorax allardycei (Hymenoptera, Formicidae): time budgets and the evolution of worker reproduction. Behav Ecol Sociobiol 18:165-173

Crosland MW (1990) The influence of the queen, colony size and worker ovarian development on nestmate recognition in the ant Rhytidoponera confusa. Anim Behav 39:413-425

Dugatkin LA, Reeve HK (2000) Game theory and animal behavior. Oxford University Press, New York

Fletcher DJ, Ross KG (1985) Regulation of reproduction in eusocial Hymenoptera. Ann Rev Entomol 30:319-343

Franks NR, Partridge LW (1993) Lanchester battles and the evolution of combat in ants. Anim Behav 45:197-199

Fukumoto Y (1983) A new method for studying the successive change of colony composition of the ants in the field. Biol Mag Okinawa 21:27-31

Fukumoto Y, Abe T, Taki A (1989) A novel form of colony organization in the "queenless" ant Diacamma rugosum. Physiol Ecol Japan 26:55-61
Heinze J, Foitzik S, Hippert A, Hölldobler B (1996) Apparent dear-enemy phenomenon and environment-based recognition cues in the ant Leptothorax nylanderi. Ethology 102:510-522

Hölldobler B, Wilson EO (1978) The multiple recruitment systems of the African weaver ant Oecophylla longinoda (Latreille) (Hymenoptera: Formicidae). Behav Ecol Sociobiol 3:19-60

Hölldobler B, Wilson EO (1990) The ants. Harvard University Press, Cambridge

Jaeger RG (1981) Dear enemy recognition and the costs of aggression between salamanders. Am Nat 117:962-974

Kikuchi T, Nakagawa T, Tsuji K (2008) Changes in relative importance of multiple social regulatory forces with colony size in the ant Diacamma sp. from Japan. Anim Behav 76:2069-2077

Langen TA, Tripet F, Nonacs P (2000) The red and the black: habituation and the dear-enemy phenomenon in two desert Pheidole ants. Behav Ecol Sociobiol 48:285-292

Mayade S, Cammaerts MC, Suzzoni JP (1993) Home-range marking and territorial marking in Cataglyphis cursor (Hymenoptera, Formicidae). Behav Proc 30:131-142

Molet M, Van BM, Monnin T (2005) Dominance hierarchies reduce the number of hopeful reproductives in polygynous queenless ants. Insect Soc 52:247-256

Monnin T, Ratnieks FL, Brandão CR (2003) Reproductive conflict in animal societies: hierarchy length increases with colony size in queenless ponerine ants. Behav Ecol Sociobiol 54:71-79

Morisita M, Kubota M, Onoyama K (1989) A guide for the identification of Japanese ants. I. Ponerinae, Cerapachyinae, Pseudomyrmecinae, Dorylinae and Leptanillinae (Hymenoptera: Formicidae). Myrmecol Soc Japan, Tokyo

Newey PS, Robson SK, Crozier RH (2010) Weaver ants Oecophylla smaragdina encounter nasty neighbors rather than dear enemies. Ecology 91:2366-2372

Paul B, Paul M, Annagiri S (2016) Opportunistic brood theft in the context of colony relocation in an Indian queenless ant. Sci Rep 6:36166

Plowes NJ, Adams ES (2005) An empirical test of Lanchester's square law: mortality during battles of the fire ant Solenopsis invicta. Proc R Soc B 272:1809-1814

Smith JM, Price GR (1973) The logic of animal conflict. Nature 246:15

Stuart RJ (1984) Experiments on colony foundation in the slave-making ant Harpagoxenus canadensis MR Smith (Hymenoptera; Formicidae). Can J Zool 62:1995-2001

Stuart RJ (1991) Nestmate recognition in leptothoracine ants: testing for effects of queen number, colony size and species of intruder. Anim Behav 42:277-284

Stuart RJ, Alloway TM (1983) The slave-making ant, Harpagoxenus canadensis MR Smith, and its host-species, Leptothorax muscorum (Nylander): slave raiding and territoriality. Behaviour 85:58-89

Stuart RJ, Herbers JM (2000) Nest mate recognition in ants with complex colonies: within- and between-population variation. Behav Ecol 11:676-685

Suwabe M, Ohnishi H, Kikuchi T, Tsuji K (2007) Nestmate discrimination in the queenless ponerine ant Diacamma sp. from Japan. Entomol Sci 10:7-10

Tsuji K (2010) What brings peace to the world of ants (Hymenoptera: Formicidae). Myrmecol News 13:131-132

Tsuji K (2013) Kin selection, species richness and community. Biol Lett 9:20130491

Tsuji K, Ito Y (1986) Territoriality in a queenless ant, Pristomyrmex pungens (Hymenoptera: Myrmicinae). Appl Entomol Zool 21:377-381

Uezu K (1977) On the foraging activity of Diacamma rugosum (Le Guillon). Biol Mag Okinawa 15:5-17

Wittlinger M, Wehner R, Wolf H (2006) The ant odometer: stepping on stilts and stumps. Science 312:1965-1967

Publisher's Note Springer Nature remains neutral with regard to jurisdictional claims in published maps and institutional affiliations. 